to re-evaluate the benefit of vaccination against influenza in children.

\section{SUBCUTANEOUS HUMAN HEPATITS B IMMUNOGLOBULIN (FOVEPTA) IN NEONATES OF HBV-CARRIER MOTHERS}

doi:10.1136/archdischild-2012-302724.1834

${ }^{1} \mathrm{R}$ Schloesser, ${ }^{2} \mathrm{~W}$ Kamin, ${ }^{3} \mathrm{G}$ Kriván, ${ }^{3} \mathrm{P}$ Siklós, ${ }^{4} \mathrm{~W}$ Mendling, ${ }^{1} \mathrm{H}$ Buxmann. ${ }^{1}$ Neonatology, Goethe-University Frankfurt/Main, Frankfurt/Main; ${ }^{2}$ Neonatology; Protestant Hospital for Children and Adolescents; Hamm; Germany; ${ }^{3}$ Neonatology, St. Stephen Hospital, Budapest, Hungary; ${ }^{4}$ Gynecology, Vivantes Hospital Friedrichshain, Berlin, Germany

Background and Aims Postnatal active and passive immunization is recommended for prevention of hepatits-B-virus (HBV) transmission in any offspring of a HBV-carrier mother. To improve convenience in application for neonates and for doctors we studied the efficacy and safety of a subcutaneous (s.c.) human hepatitis B immunoglobulin (Fovepta).

Methods In an open, prospective multicenter trial neonates of HBV carrier mothers were randomized to receive a single dose of the high concentrated human hepatitis immunoglobulin Fovepta (200 IU, $0.4 \mathrm{ml}$ ) either subcutaneously or intramuscularly (i.m.). The passive immunization was combined with an active vaccination against hepatits B. Efficacy was defined as an anti-HBs-serum concentration of $>100$ IU/L 48 to 72 hours post vaccination. Adverse events (AE) were documented during hospital stay and follow-up surveillance of 7-15 months.

Results 31 neonates were included (17 s.c. and 14 i.m.). One infant of the s.c. group had a post-dose anti-HBs level of $81.0 \mathrm{IU} / \mathrm{l}$. All other study patients reached a level of $>100$ IU/1. AEs were more often in i.m. group patients, but without statistical significance. There was no AE, which led to discontinuation from the study. 24 of 31 infants completed the follow up period. No hepatits B breakthrough infection was observed.

Conclusions Subcutaneous vaccination with a high concentrated hepatitis immunoglobulin (Fovepta) is effective and safe in newborn infants.

(Main results of the study are accepted for publication in J Perinat Med).

\section{LIVE ATTENUATED VACCINES INDUCE GUT CATHELICIDIN ANTIMICROBIAL PEPTIDE RESPONSE IN NEONATES - A NATURAL EXPERIMENT}

doi:10.1136/archdischild-2012-302724.1835

SM Ahmad, M Rashid, J Alam, R Raqib. Systems Vaccinology Group, Center for Vaccine Sciences, ICDDR, B, Dhaka, Bangladesh

Background and Aims Oral polio (OPV) and BCG vaccines are recommended to be given at birth for protection against tuberculosis and polio, while observational studies in developing countries demonstrate reduction of mortality from infections other than target disease. The mechanism of such non-specific beneficial effects is unknown. We investigated gut antimicrobial peptides response during neonatal period who had received these vaccines simultaneously within 48-hour of birth.

Methods In a cross sectional study design, stool samples were collected from infants at 1 month of age who had $(n=36)$ or had not $(n=42)$ received both vaccines within $48 \mathrm{~h}$ of birth. Antimicrobial peptides- human cathelicidin (LL37) were measured in the extracted stool samples by ELISA. Demographic and anthropometric data were collected from the clinic and structured questionnaires.

Results Infants of the vaccinated group had 39.8\% higher excretion of LL37 in stool at 1 month of age $(\mathrm{P}=0.02)$. Such induction is observed only to the infants who born normally $(\mathrm{P}=0.01)$. Sex difference had no effect. Multivariate analysis showed higher LL37 response $(\mathrm{P}=0.08)$ among vaccinated infants after adjusting for sex, place of birth, mother age, postnatal age and mode of delivery. Including birth weight along with other variables indicates birth weight is significant predictor of $\operatorname{LL37}(\mathrm{P}=0.05)$ irrespective of vaccination status.

Conclusions Induction of mucosal antimicrobial peptide LL-37 following on-birth live attenuated vaccination may provide protection against other infections and possible explain the observed nonspecific survival benefit in developing countries where low birth weight remains significant public health problem.

\section{INFLAMMATORY RESPONSES TO HEPATITIS B VIRUS VACCINE AMONG HEALTY TERM INFANTS AT BIRTH}

doi:10.1136/archdischild-2012-302724.1836

'I Çelik, 'G Demirel, 'FE Canpolat, ' 0 Erdeve, 1,2U Dilmen. 'Neonatology, Zekai Tahir Burak Maternity Teaching Hospital; ' 2 Pediatrics, Yildirim Beyazit University, Faculty of Medicine, Ankara, Turkey

Hepatitis B virus (HBV) infection continues to be a serious global health problem. Primary prevention through immunization remains the most effective way of controlling the spread of HBV. HBV vaccines are immunogenic in newborns and infants, and provide high seroprotection. During the course of HBV vaccination, we observed that substantial number of term infants had elevated CRP values without sepsis. Therefore, we prospectively studied IL- 6 and CRP responses to $\mathrm{HBV}$ immunization, seeking to demonstrate that immunization stimulates elevation of IL- 6 and CRP levels without clinical detoriation, and that usually there is no need for antibiotic treatment.

Subjects for the study were healty term infants without signs and symptoms of sepsis. IL-6, CRP, and white blood cell (WBC) levels were determined before immunization and 24 hours after immunization

Study population included 70 infants. Significant increases in CRP were seen $24 \mathrm{hr}$ after vaccination $(\mathrm{p}=0.000)$. Although CRP levels of 22 infants (31.4\%) at second evaluation were above the cut-off $(4.82 \mathrm{mg} / \mathrm{ml})$, none of these infants had clinical symptoms of sepsis. After 48-72 hours, CRP level of all patients normalized with no blood culture positivity.

In conclusion, our study showed that HBV vaccine is highly immunogenic and responsible for CRP elevation in term infants without sepsis after first vaccination at birth. To the best of our knowledge this is the first study evaluating CRP response to HBV vaccine at birth in term infants. We suggest that this response should be encountered in differentiation of early neonatal sepsis to avoid unnecessary antibiotic use.

\section{EVALUATION OF IMMUNE RESPONSE TO HEPATITIS B VACCINE IN THE INFANTS DISCHARGED FROM NEONATAL INTENSIVE CARE UNIT}

doi:10.1136/archdischild-2012-302724.1837

${ }^{1} \mathrm{FC}$ Kilic, ${ }^{2} \mathrm{~N}$ Tekin, ${ }^{3} \mathrm{EC}$ Dinleyici, ${ }^{2} \mathrm{~A}$ Aksit. ${ }^{1}$ Pediatrics; ${ }^{2}$ Dept. of Pediatrics, Division of Neonatology: ${ }^{3}$ Pediatrics, PICU, Eskisehir Osmangazi University, Eskisehir, Turkey

The Aim of this study is to evaluate the effect of presumed risk factors on antiHBs response to vaccination in NICU graduates. The study group consisted of 150 infants (105 term, 45 preterm) who were discharged from the NICU. Hepatitis B vaccine was administered according to birth weight adjusted schedule. Infants with birth weight less than $2000 \mathrm{~g}$ were vaccinated at intervals of 0.1 .2 and 12 months. Other infants were vaccinated with $0,1,6$ months schedule. AntiHBs titers were studied 3 weeks to 2 months after the last vaccine dose. AntiHBs titers were classified into 4 groups as < 10mIU/mL, 11-99 mIU/mL, 100-999 mIU/mL, >1000 $\mathrm{mIU} / \mathrm{mL}$ consequently. Distribution of the antiHBs levels of preterm infants were different than term infants $(p<0.05)$. Antibody 